\title{
EXPERIMENTAL ANALYSIS OF THERMAL EFFICIENCY IMPROVEMENT DUE TO HIGH EGR RATIO IN HCCI ENGINES FUELLED WITH DME AND NATURAL GAS
}

\author{
* Masahiro Ishida, Sukho Jung, Hironobu Ueki and Daisaku Sakaguchi \\ Graduate School of Science and Technology, Nagasaki University \\ 1-14 Bunkyo-machi, Nagasaki 852-8521, Japan
}

Key Words: HCCI, DME, Natural gas, EGR, Thermal efficiency

\begin{abstract}
The effect of exhaust gas recirculation (EGR) on combustion characteristics and thermal efficiency has been investigated in homogeneous charge compression ignition (HCCI) engines using diesel engines with single- and multi-cylinder having compression ratios of 17.8 and 18.2 respectively. These HCCI engines were operated by natural gas premixed with a small amount of dimethyl ether (DME) as an ignition source. In the present study, the effect of EGR was focused on improvement in the brake thermal efficiency. It is noticed that the brake thermal efficiency higher than $4 \%$ was achieved by the high EGR ratio of 0.5 compared with the case without EGR, and almost equal improvements due to EGR are obtained in both single- and multi-cylinder engines. It is found that an increase in brake thermal efficiency due to EGR is based on the improvement in combustion efficiency mainly resulting from a significant reduction in the unburned hydrocarbon emission.
\end{abstract}

\section{INTRODUCTION}

Recent researches into reducing both NOx and particulate emissions simultaneously and increasing thermal efficiency in diesel engines have shown that a homogeneous charge compression ( $\mathrm{HCCl}$ ) engine will be a promising way to accomplish these targets. A HCCI engine fuelled with DME alone showed some problems with respects to the ignition timing control, the large amount of unburned hydrocarbon emission, and the limited load operation range due to misfire and knock. It is a key technology to control the ignition timing by adopting chemical and physical countermeasures. In the recent studies by Chen, et al. [1, 7], Konno, et al. [8], Iida, et al. [9] and Ishida, et al. [2], it was clarified theoretically and/or experimentally that natural gas shows a strong effect on suppression of the low temperature reaction (LTR) of DME, resulting in a proper retardation of the high temperature reaction (HTR) toward near TDC.

In the authors' preceding studies $[2,10]$ with respect to a HCCI engine fuelled with DME and natural gas, the effects of intake temperature, compression ratio and EGR on LTR and HTR, misfire limit, knock limit, exhaust emissions and thermal efficiency were investigated in a single-cylinder HCCI engine, and it was shown that the highest load could be achieved under the minimum DME amount condition for stable ignition. The minimum DME amount for stable ignition and operation has been investigated in a four-cylindered HCCI engine comparing with the results of the single cylinder HCCI engine, focusing on cylinder-to-cylinder variations of exhaust gas temperature and cylinder liner temperature in relation to the branching passage structure of intake manifold and the cooling passage system in the multi-cylinder engine (Ishida, et al. [11]).

In the previous study (Ishida, et al. [3], Tagai, et al. [4]) with respect to a dual fuel diesel engine fuelled with natural gas and a small amount of gas oil as an ignition source, the effect of EGR on NOx was investigated. As a result, a significant improvement in the trade-off between NOx and PM is achieved in both low and high loads mainly by integrating the premixed charge of natural gas with the minimum injection amount of gas oil and EGR as well. It is found that the NOx-PM trade-off can be drastically improved by a dual fuel diesel engine without deteriorating the thermal efficiency. On the other hand, in a HCCI engine fuelled with natural gas and 
DME, EGR is not always necessary because both NOx and PM are inherently very close to zero. The effect of internal EGR on combustion efficiency and indicated thermal efficiency in a natural-gas HCCI engine were investigated by Sako, et al. [5], and a combination with internal EGR and external EGR was adopted to control combustion phasing by Ohmura, et al. [6].

In the present study, EGR was adopted in a multi-cylinder HCCI engine as well as a single-cylinder one to obtain a higher thermal efficiency as well as a wider operation load range. Focus is put especially on the effect of EGR on the brake thermal efficiency improvement and the target is to clarify the reason why the efficiency is improved by EGR.

\section{EXPERIMENTAL SETUP}

One of the test engines was a four-cylindered high-speed naturally aspirated direct injection diesel engine, the type 4JB1-2 manufactured by ISUZU Motors Ltd. The principal particulars are shown in Table 1; the bore is 93 [mm], the stroke is $102[\mathrm{~mm}]$, the maximum output is $61.8[\mathrm{~kW}]$ at 3400 [rpm], and the compression ratio is $\varepsilon=18.2$. Another test engine with single-cylinder was used for comparison, the type NFD 170-(E) manufactured by YANMAR Co., Ltd.; the bore is 102 [mm], the stroke is $105[\mathrm{~mm}]$, the maximum output is $12.5[\mathrm{~kW}]$ at $2400[\mathrm{rpm}]$, and the compression ratio is $\varepsilon=17.8$, as is also shown in Table 1 .

Fuel supply system of the test engine is shown in Fig.1, DME and the compressed natural gas were charged into the intake air at the pressures of 0.12 and $0.10[\mathrm{MPa}]$ respectively after measuring each flow rate. In order to obtain a homogeneous charge and to change the fraction of natural gas in the charged mixture, DME, natural gas and EGR gas as well were charged independently each other into the mixing chamber located at 1,800 $\mathrm{mm}$ upstream of the intake manifold. A similar experimental setup was built for the singlecylinder test engine.

Table 1 Specification of test engines

\begin{tabular}{|l|c|c|}
\hline \multicolumn{1}{|c|}{ Specifications } & 1 cylinder & 4 cylinders \\
\hline Engine type & YANMAR & ISUZU \\
& NFD170-(E) & $4 J B 1-2$ \\
Cycle & 4 & 4 \\
Cooling system & Water & Water \\
Bore $\times$ Stroke [mm] & $102 \times 105$ & $93 \times 102$ \\
Displacement volume [cc] & 857 & 2771 \\
Compression ratio & 17.8 & 18.2 \\
Maximum power & $12.5 / 2400$ & $61.8 / 3400$ \\
{$[\mathrm{~kW} / \mathrm{rpm}]$} & & \\
\hline
\end{tabular}

Properties of test fuels are shown in Table 2; DME as an ignition source is $99.9[\%]$ in purity and has a cetane number about 60 as high as gas oil. Natural gas as a main fuel is a city gas named " $13 \mathrm{~A}$ " in Japan, which consists of about $88 \%$ of $\mathrm{CH}_{4}$ and the others of $\mathrm{C}_{2} \mathrm{H}_{6}$, $\mathrm{C}_{3} \mathrm{H}_{8}$ and etc. The lower heating values of these fuels are 28.9 and $49.1[\mathrm{MJ} / \mathrm{kg}]$ respectively.

Table 2 Properties of test fuels

\begin{tabular}{|c|c|c|c|}
\hline & Gas oil & DME & Natural gas \\
\hline Chemical structure & 0.8378 & $\mathrm{CH}_{3} \mathrm{OCH}_{3}$ & $\begin{array}{c}\mathrm{CH}_{4}(88 \%) \\
\text { +Others }\end{array}$ \\
\hline $\begin{array}{l}\text { Lower heating } \\
\text { value }[\mathrm{MJ} / \mathrm{kg}]\end{array}$ & 42.9 & 28.9 & 49.1 \\
\hline Cetane number & 55 & 60 & 0 \\
\hline Ignition point $[\mathrm{K}]$ & 520 & 620 & 920 \\
\hline Stoichio. A/F ratio & 14.50 & 8.98 & 17.10 \\
\hline$\%$ wt.Carbon & 86.5 & 52.2 & 79.4 \\
\hline$\%$ wt.Hydrogen & 13.5 & 13.0 & 20.6 \\
\hline$\%$ wt.Oxygen & 0 & 34.8 & 0.0 \\
\hline
\end{tabular}

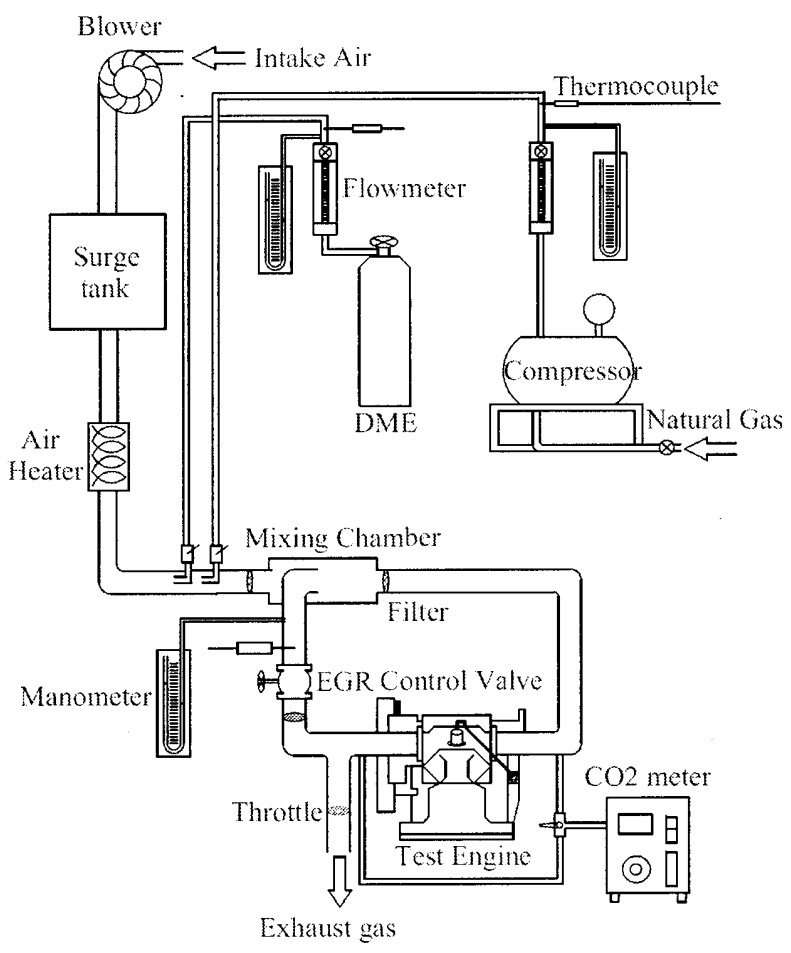

Fig.1 Fuels supply and EGR system

The combustion tests were carried out at $50 \%$ of the rated speed each; $1,700 \pm 5[\mathrm{rpm}]$ for the multi-cylinder engine and $1,200 \pm 5[\mathrm{rpm}]$ for the single-cylinder engine. The suction air pressure at the intake manifold was adjusted at $0.1013[\mathrm{MPa}$ ] by using the electric blower. For finding the minimum DME amount for stable ignition, the amount of DME was decreased as the amount of natural gas was increased while the engine load was kept constant. And, in order to find the maximum operation load, the engine load was increased by increasing the natural gas charge-rate while keeping the amount of DME constant respectively. At the minimum DME amount condition, the EGR ratio was 
changed stepwise from 0 to 0.5 keeping intake temperature constant at $\mathrm{T}_{\mathbb{I N}}=60\left[{ }^{\circ} \mathrm{C}\right]$ by using the electric heater even in the case with EGR, in other word, the cooled EGR was adopted.

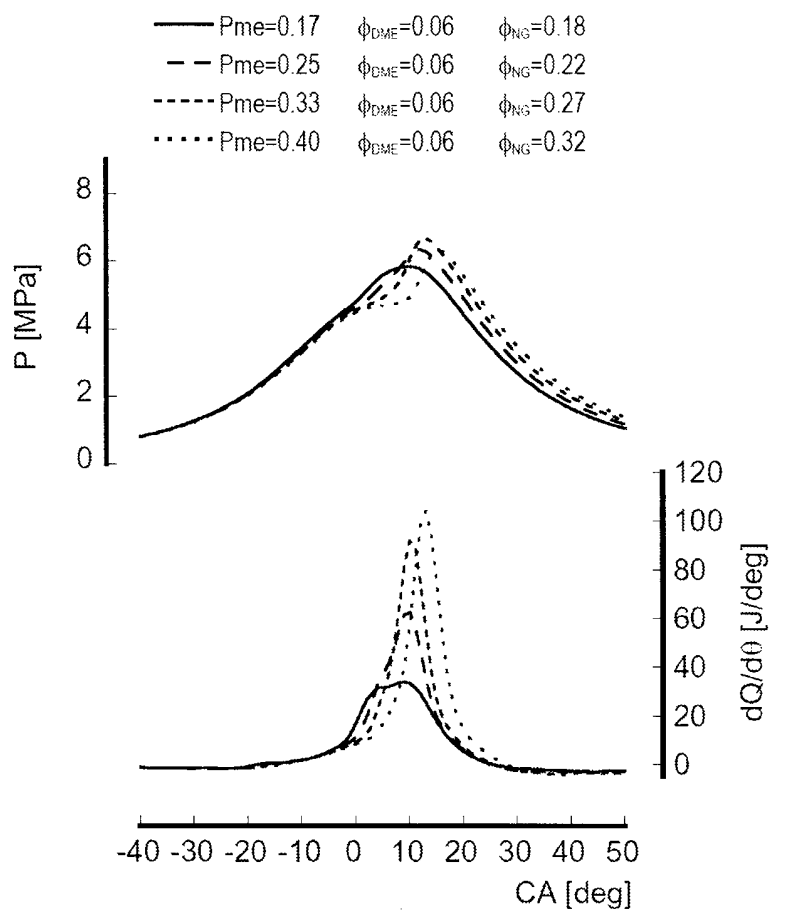

(a) $\mathrm{X}_{\mathrm{EGR}}=0$

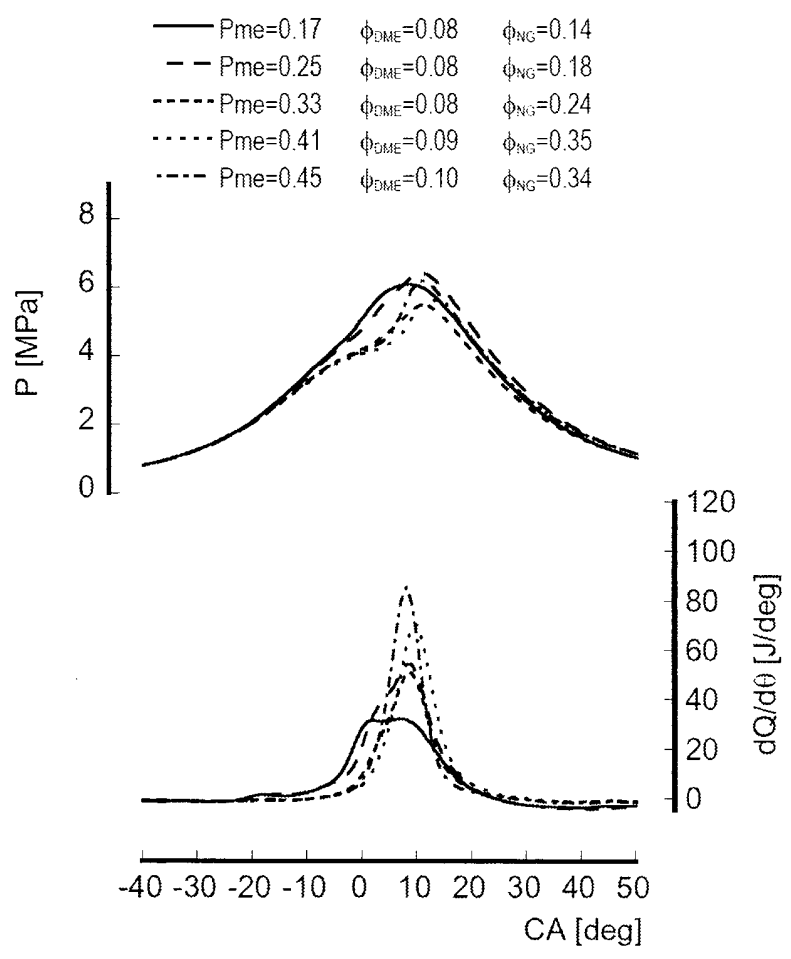

(b) $\mathrm{X}_{\mathrm{EGR}}=0.4$

Fig.2 Change in combustion history due to engine load in multi-cylinder $\mathrm{HCCI}$ engine $\left(\mathrm{T}_{\mathrm{IN}_{\mathrm{N}}}=60\left[{ }^{\circ} \mathrm{C}\right]\right)$
The time history of in-cylinder pressure was measured using a quartz pressure sensor and this output was sampled every one-fourth degree of crank angle by means of the four channel combustion analyzer "CB-467" manufactured by Ono Sokki Co. Ltd. The time history of combustion pressure was the ensemble average sampled over continuous 350 engine cycles. Those data were transmitted to the personal computer and recorded on hard disks.

$\mathrm{CO}_{2}$ concentration [\%] was measured at both intake and exhaust manifolds respectively to calculate the EGR ratio $X_{\mathrm{EGR}}[\mathrm{kg} / \mathrm{kg}]$. With respect to the exhaust gas analysis, smoke density [Bosch], concentrations of nitrogen oxides NOx [ppm], the total unburned hydrocarbon THC [ppm], carbon monoxide $\mathrm{CO}$ [ppm] and the exhaust gas temperature $\mathrm{Te}\left[{ }^{\circ} \mathrm{C}\right]$ were measured by using the respective sensors.

\section{RESULTS AND DISCUSSIONS}

Figures 2(a) and (b) show combustion time-history change due to engine load in the case of the multicylinder engine. $\mathrm{P}[\mathrm{MPa}]$ and $\mathrm{dQ} / \mathrm{d} \theta[\mathrm{J} / \mathrm{deg}]$ in the ordinate denote the measured in-cylinder pressure and the apparent heat release rate respectively, and the abscissa denotes the crank angle CA [deg]. $\phi_{\mathrm{DME}}$ and $\phi_{\mathrm{NG}}$ denote the equivalence ratios of DME and natural gas respectively. Fig.2(a) shows the case of $\mathrm{X}_{\mathrm{EGR}}=0$ at the minimum and constant DME equivalence ratio of $\phi_{\mathrm{DME}}=0.06$ and Fig.2(b) is that of $\mathrm{X}_{\mathrm{EGR}}=0.4$ running at the minimum DME amount condition for stable ignition, where the minimum DME equivalence ratio increases a little from $\phi_{\mathrm{DME}}=0.08$ at the low load to $\phi_{\mathrm{DME}}=0.10$ at the high load. The load was increased from Pme $=0.17$ [MPa] to the knock limit load of $P m e=0.40$ or 0.45 $[\mathrm{MPa}]$ by increasing the natural gas charge rate keeping the DME amount almost constant. A strong effect of natural gas on suppression of the low temperature reaction (LTR), the LTR is suppressed significantly with increase in engine load, then, the peak timing of HTR is retarded to about 10 [deg.CA ATDC] at the high load near knock limit, which is almost identical in both cases (a) and (b). It was shown in the literature [8] that, as the EGR ratio increases, the LTR in the heat release curve varies little, however, the HTR is suppressed remarkably. As the EGR ratio increases, the minimum $\phi_{\text {DME }}$ for stable ignition increases, in other words, the larger ignition energy is required in the larger EGR ratio because the in-cylinder gas temperature is lowered due to increases in $\mathrm{H}_{2} \mathrm{O}$ and $\mathrm{CO}_{2}$ gases having high specific heat. It is clear from Figs. 2(a) and (b) that the maximum heat release rate of HTR is fairly lower in spite of the larger DME amount in $\mathrm{X}_{\mathrm{EGR}}=0.4$ than $\mathrm{X}_{\mathrm{EGR}}=0$. The maximum engine load of $\mathrm{Pme}=0.40[\mathrm{MPa}]$ as the knock limit was attained at the small DME amount of $\phi_{\mathrm{DME}}=0.06$ in the case of $X_{E G R}=0$, while that of $P m e=0.45[\mathrm{MPa}]$ was attained at the larger $\mathrm{DME}$ amount of $\phi_{\mathrm{DME}}=0.10$ in $\mathrm{X}_{\mathrm{EGR}}=0.4$. It is convinced that the high temperature reaction can be suppressed by EGR. 


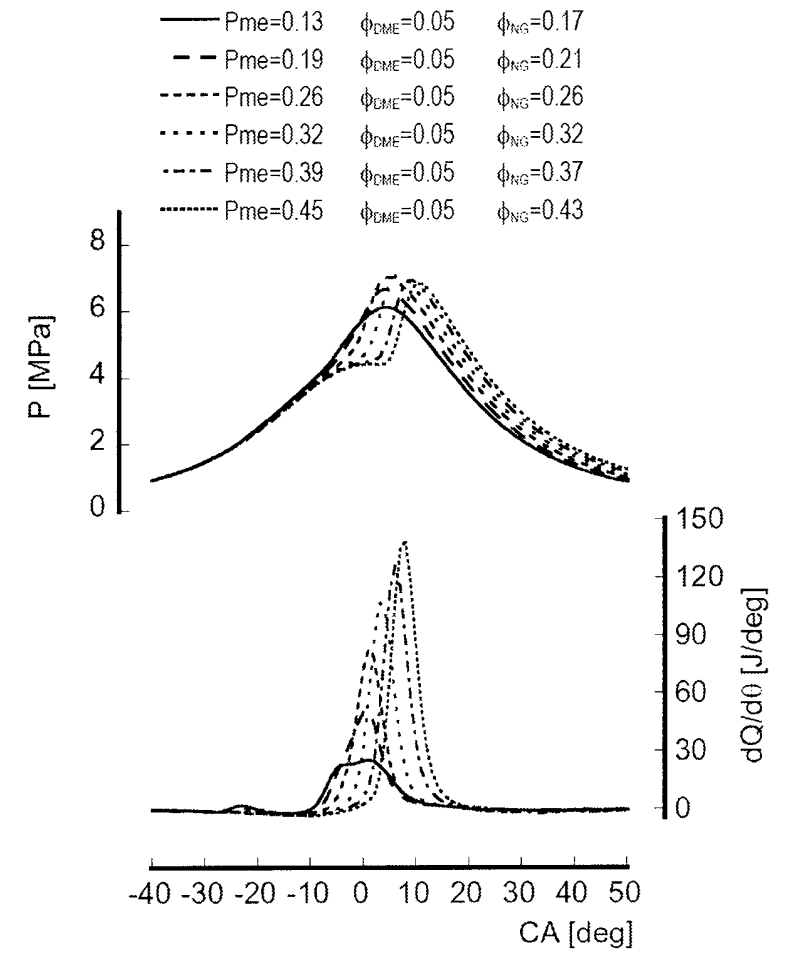

(a) $\mathrm{X}_{\mathrm{EGR}}=0$

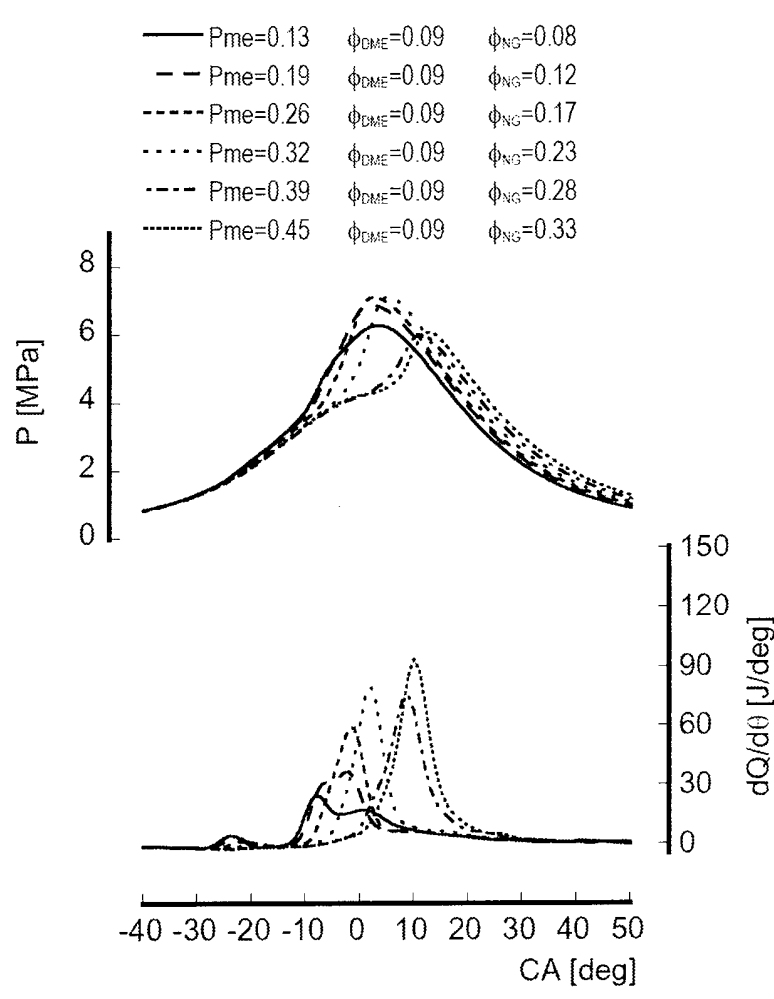

(b) $\mathrm{X}_{\mathrm{EGR}}=0.5$

Fig.3 Change in combustion history due to engine load in single-cylinder $\mathrm{HCCI}$ engine $\left(\mathrm{T}_{\mathbb{N}}=60\left[{ }^{\circ} \mathrm{C}\right]\right)$

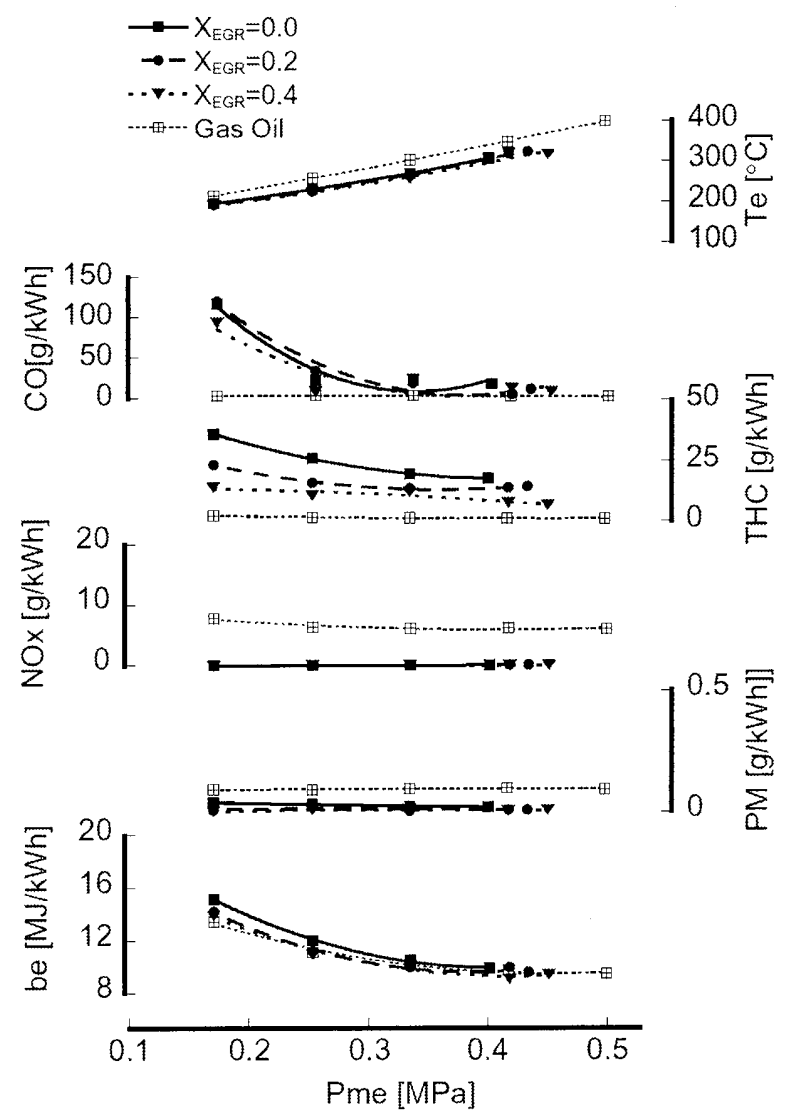

Fig.4 Effect of EGR ratio on exhaust emissions and fuel consumption in multi-cylinder HCCI engine $\left(\mathrm{T}_{\mathrm{IN}}=60\right.$ $\left.\left[{ }^{\circ} \mathrm{C}\right]\right)$
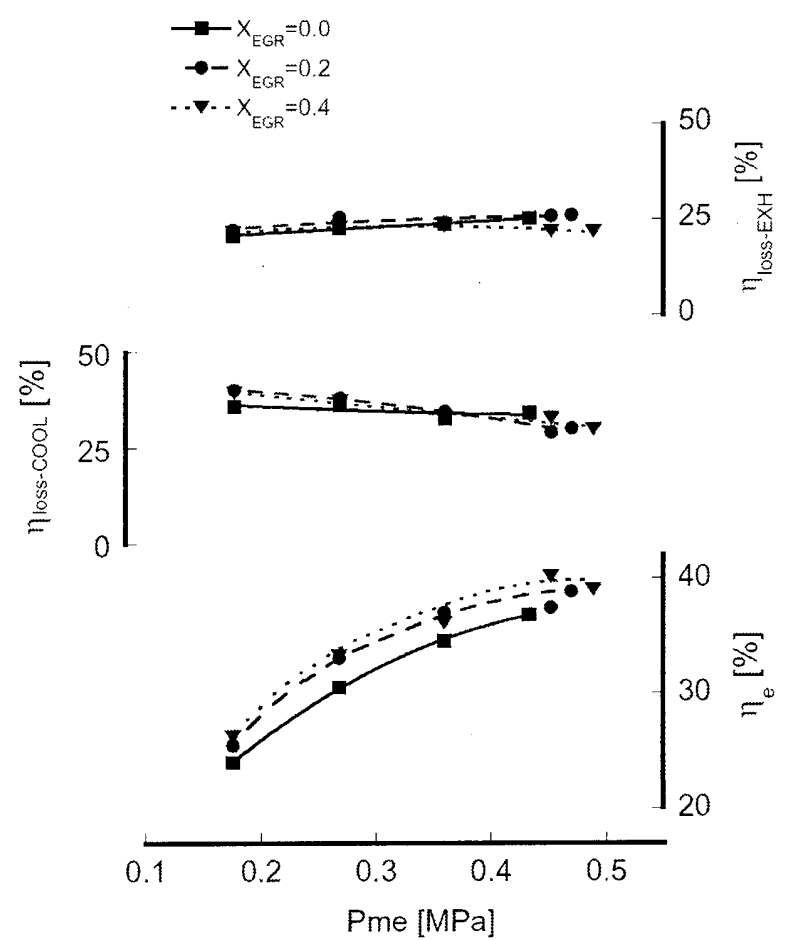

Fig. 5 Effect of EGR ratio on heat balance in multicylinder $\mathrm{HCCI}$ engine $\left(\mathrm{T}_{\mathrm{IN}}=60\left[{ }^{\circ} \mathrm{C}\right]\right)$ 
Figures 3(a) and (b) show combustion time-history change due to engine load in the case of the singlecylinder engine. Fig.3(a) shows the case of $X_{E G R}=0$ at the minimum and constant DME equivalence ratio of $\phi_{\mathrm{DME}}=0.05$ and Fig.3(b) is that of $\mathrm{X}_{\mathrm{EGR}}=0.5$ at the minimum DME amount of $\phi_{\mathrm{DME}}=0.09$. The change in combustion behavior is almost similar in both HCCI engines with single- and multi-cylinder. The maximum engine load of $\mathrm{Pme}=0.45[\mathrm{MPa}]$ was achieved in the case of $\mathrm{X}_{\mathrm{EGR}}=0$, and the equal maximum load of $\mathrm{Pme}=0.45$ $[\mathrm{MPa}]$ was attained in $\mathrm{X}_{\mathrm{EGR}}=0.5$.

Figure 4 shows the effect of EGR on exhaust emissions and fuel consumption $[\mathrm{MJ} / \mathrm{kWh}]$ in the multi-cylinder $\mathrm{HCCI}$ engine with $\mathrm{X}_{\mathrm{EGR}}=0,0.2$ and 0.4 . The gray dotted line denotes the case of diesel engine fuelled with gas oil for comparison. Furthermore, PM $[\mathrm{g} / \mathrm{kWh}]$ was reduced from Bosch smoke density by using the relation between soot and smoke density. It is reasonable that, as the engine load increases, the fuel consumption decreases, then, the brake thermal efficiency increases in all cases. The maximum engine load of Pme $=0.45[\mathrm{MPa}]$ is attained in the HCCI engine with the high EGR ratio of $\mathrm{X}_{\mathrm{EGR}}=0.4$, which is small compared with the diesel engine case. In the HCCI engine, both NOx and PM are very close to zero regardless of the EGR ratio, and $\mathrm{CO}$ emission is changed little by EGR. It is noticed that the fuel consumption and the THC emission are reduced remarkably over the whole operation range as the EGR ratio increases. The reduction in THC might be due to decrease in the natural gas charge resulting from the reduced fuel consumption.

Figure 5 shows the effect of EGR on the exhaust loss, the cooling loss and the brake thermal efficiency based on the heat balance analysis. It is clearly seen that the exhaust loss and the cooling loss as well are almost unchanged by EGR within the measurement accuracy. It is noticed that the brake thermal efficiency is improved in the whole load range by about $3 \%$ in maximum in the case of $\mathrm{X}_{\mathrm{EGR}}=0.4$ compared with that of $\mathrm{X}_{\mathrm{EGR}}=0$. This improvement in efficiency due to EGR is not influenced by the exhaust loss and the cooling loss.

Figure 6 shows the effect of EGR on exhaust emissions and brake thermal efficiency in the singlecylinder $\mathrm{HCCI}$ engine with $\mathrm{X}_{\mathrm{EGR}}=0$ and 0.5 , comparing with the case of diesel engine fuelled with gas oil. In the single-cylinder HCCI engine, both NOx and PM are very close to zero regardless of the EGR ratio, and the fuel consumption and the THC emission are reduced remarkably by EGR, as is the same as the multi-cylinder $\mathrm{HCCl}$ engine. The maximum engine load of $\mathrm{Pme}=0.45$ $[\mathrm{MPa}]$ is achieved in the HCCI engine with and without EGR. It is noticed that, as the EGR ratio increases, the THC emission is reduced remarkably and the brake thermal efficiency is improved in the whole load range by about $4 \%$ in maximum in the case of $X_{\mathrm{EGR}}=0.5$ compared with that of $\mathrm{X}_{\mathrm{EGR}}=0$. Almost similar behavior is seen in the case of the multi-cylinder HCCI engine shown in Fig.4.

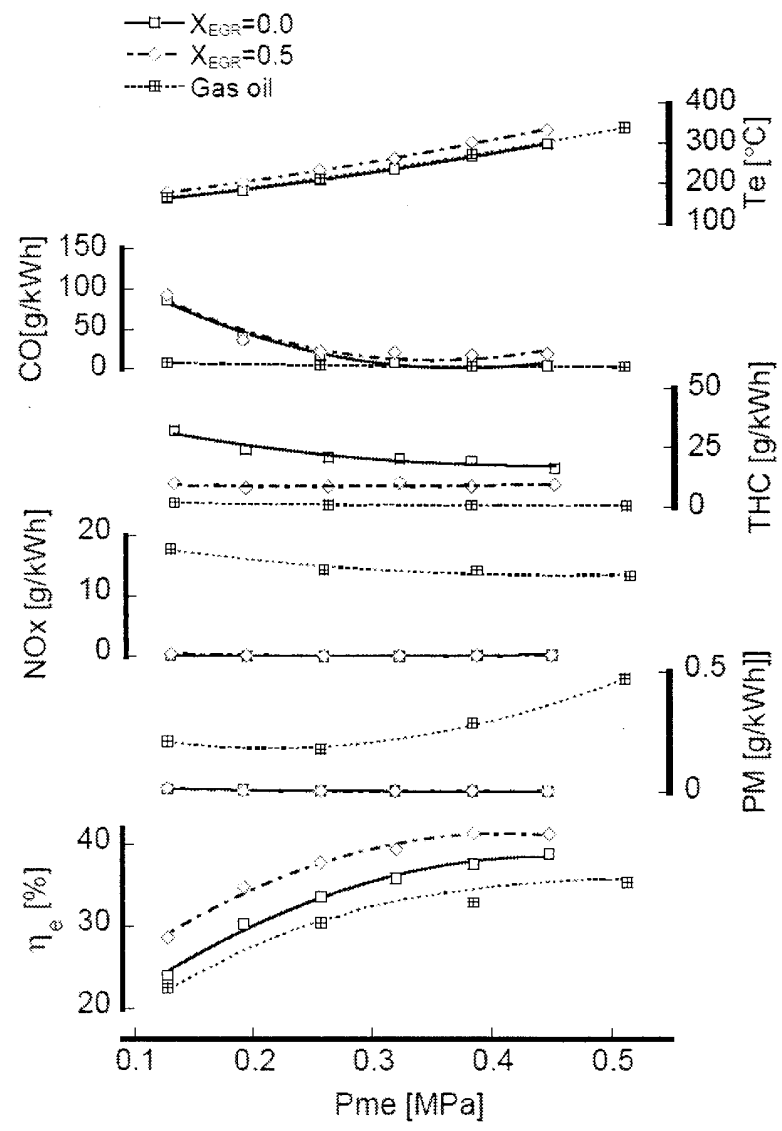

Fig.6 Effect of EGR ratio on exhaust emissions and brake thermal efficiency in single-cylinder HCCI engine $\left(\mathrm{T}_{\mathrm{IN}}=60\left[{ }^{\circ} \mathrm{C}\right]\right)$

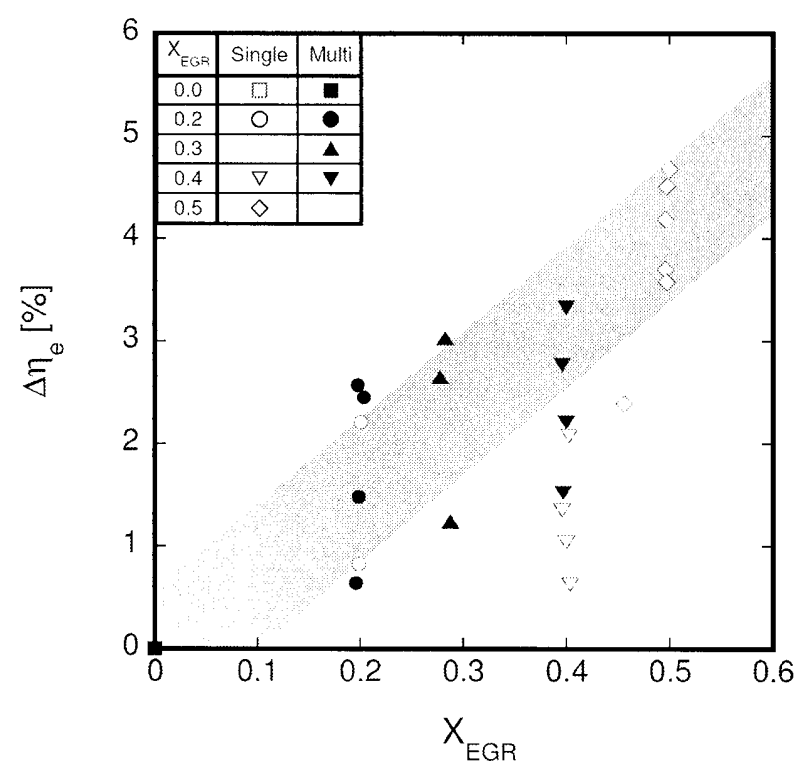

Fig.7 Correlation between brake thermal efficiency increment and EGR ratio in HCCI engines $\left(\mathrm{T}_{\mathrm{IN}}=60\left[{ }^{\circ} \mathrm{C}\right]\right)$

In order to clarify the reason why the brake thermal efficiency was improved by EGR, both correlations between the brake thermal efficiency and the EGR ratio 
and between the THC loss and the EGR ratio were examined in Figs.7 and 8. The scattering of data is inherently inevitable because these data were obtained from a small difference between two experimental data shown in Figs. 4, 5 and 6 , however, a rough trend indicated by the gray band is seen in each Figs.7 and 8 with respect to the correlation between the ordinate and the abscissa, where a group of data with different Pme is denoted by the same symbol mark. As the EGR ratio increases, the brake thermal efficiency increases and the THC loss decreases. In order to find a better correlation between the thermal efficiency and the THC loss, the change in combustion inefficiency or combustion efficiency was examined.

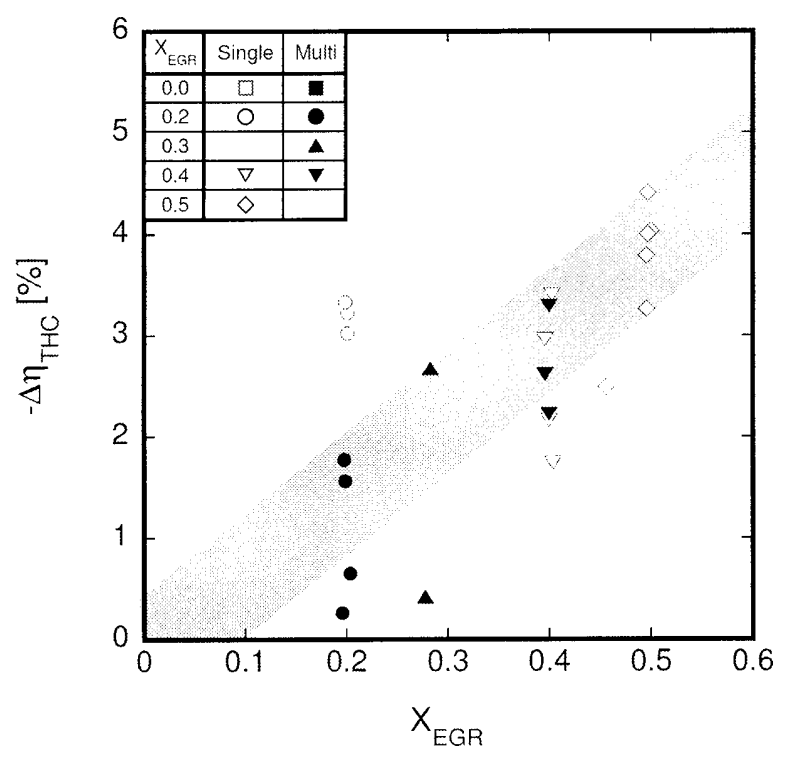

Fig. 8 Correlation between $\mathrm{THC}$ decrement and EGR ratio in $\mathrm{HCCI}$ engines $\left(\mathrm{T}_{\mathrm{IN}}=60\left[{ }^{\circ} \mathrm{C}\right]\right)$

Figure 9 shows the change due to EGR in the cumulative heat release normalized by $\mathrm{Q}_{\text {fuel }}$ in the case of multi-cylinder HCCI engine. The maximum value of the cumulative heat release indicates the apparent combustion efficiency because the cooling loss is almost unchanged by EGR as mentioned in Fig.6. Then, the difference of apparent combustion efficiencies between two cases with different EGR ratio is approximately equal to the increment of combustion efficiency $\Delta \eta_{c}$.

Figure 10 shows a clear correlation between the brake thermal efficiency increment $\Delta \eta_{\mathrm{e}}$ due to EGR and the combustion efficiency increment $\Delta \eta_{\mathrm{c}}$ due to EGR in both HCCI engines with single- and multi-cylinder. It is convinced that, in HCCI engines, the increase in brake thermal efficiency due to EGR is based on the improvement in combustion efficiency mainly resulting from a significant reduction in the unburned hydrocarbon emission

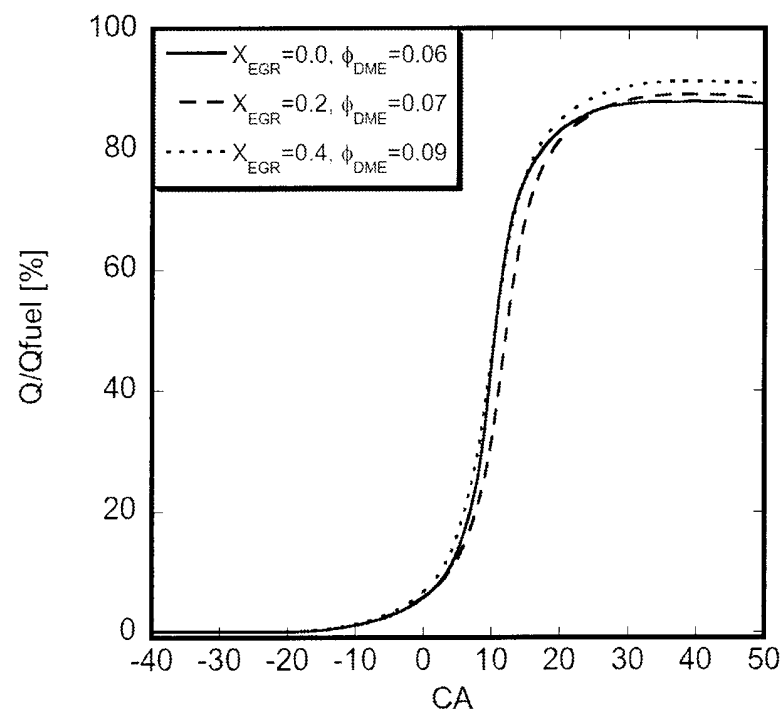

Fig.9 Change in cumulative heat release due to EGR in multi-cylinder $\mathrm{HCCI}$ engine $\left(\mathrm{T}_{\mathrm{N}}=60\left[{ }^{\circ} \mathrm{C}\right]\right.$, Pme $=0.41$ [MPa])

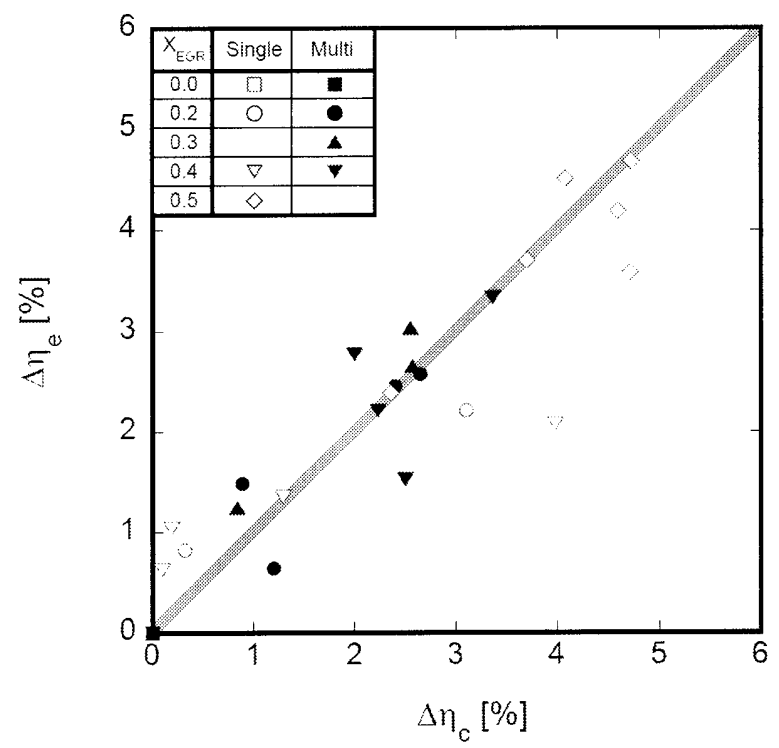

Fig.10 Correlation between brake thermal efficiency increment and combustion efficiency increment due to EGR in HCCI engines $\left(\mathrm{T}_{\mathrm{IN}}=60\left[{ }^{\circ} \mathrm{C}\right]\right)$

Figure 11 shows the change due to EGR in the indicator diagram shown as the $\log \mathrm{P}-\log \mathrm{V}$ curves, which were measured under the conditions with the EGR ratio of $0,0.2$ and 04 respectively in the multi-cylinder HCCI engine. It is clear that the polytropic index " $n$ " in the compression stroke decreases as the EGR ratio increases because the ratio of specific heats of in-cylinder gas decreases due to increases in $\mathrm{H}_{2} \mathrm{O}$ and $\mathrm{CO}_{2}$ gases having high specific heat. It seems that the lower unburned hydrocarbon emission due to EGR must be caused by the lower compression pressure. 


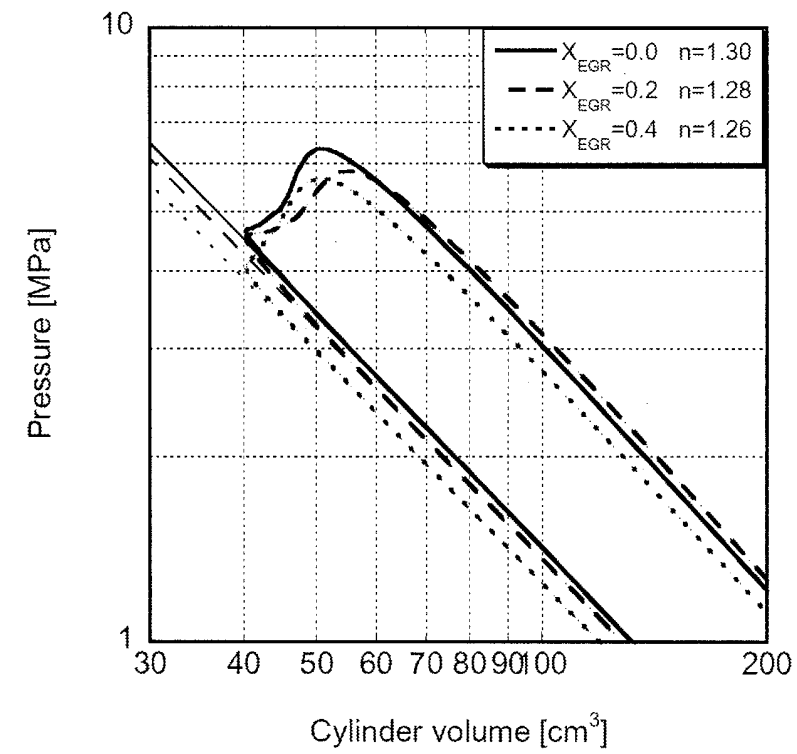

Fig.11 Change in polytropic index of compression stroke due to EGR in multi-cylinder HCCI engine $\left(\mathrm{T}_{\mathbb{N}}=60\left[{ }^{\circ} \mathrm{C}\right]\right.$, Pme $=0.41[\mathrm{MPa}]$ )

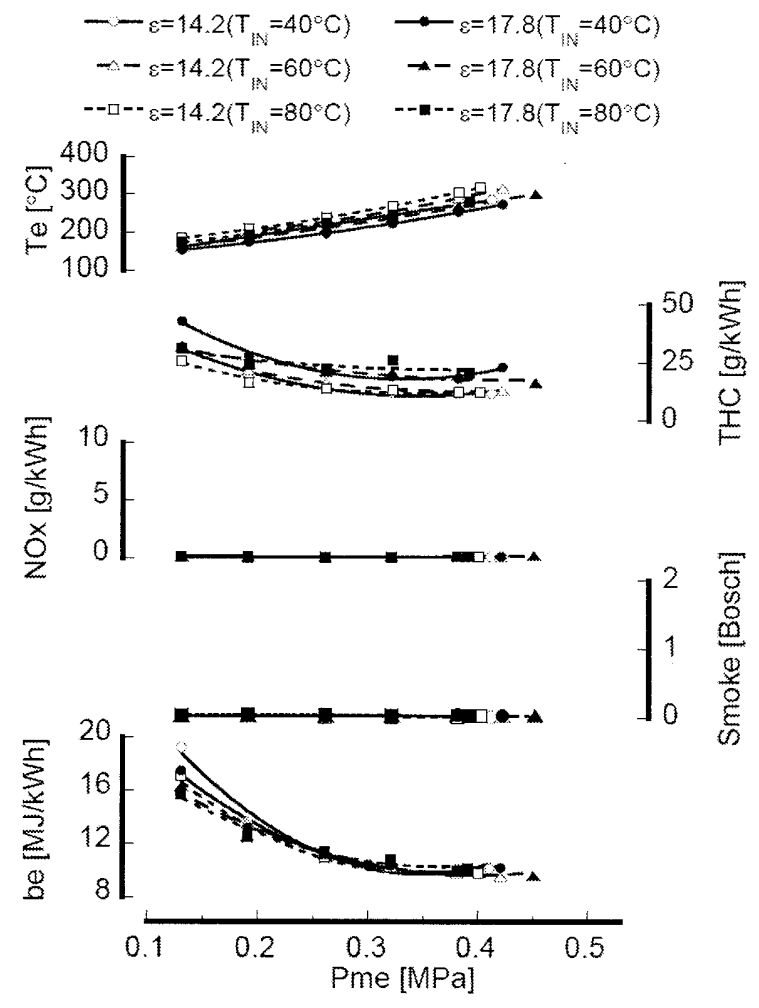

Fig.12 Effects of compression ratio $\varepsilon$ and intake temperature $T_{\mathrm{IN}}$ on exhaust emissions and brake specific fuel consumption in single-cylinder HCCI engine [11, 12]

A similar behavior was also confirmed in the experimental result shown in the references $[11,12]$, in which the compression ratio was changed. Figure 12 quoted from ref.[11] shows the effects of compression ratio and intake temperature on exhaust emissions and brake specific fuel consumption in the single-cylinder HCCI engine, the same one used in the present study. It is clearly seen that the THC emission is higher in the case of $\varepsilon=17.8$ than that of $\varepsilon=14.2$. Furthermore, the exhaust gas temperature $\mathrm{Te}$ is lower in $\varepsilon=17.8$ than $\varepsilon=14.2$, then, the brake specific fuel consumption is almost equal in the two cases with different compression ratio.

A large amount of THC emission in HCCI engines and in Otto engines as well is mainly due to the low temperature fuel pre-mixture in the crevice volume surrounded by the piston wall and cylinder liner above the top ring. The amount of fuel pre-mixture charged into the crevice volume on the compression stroke decreases as the in-cylinder pressure becomes low. This pre-mixture is released from the crevice volume into the main combustion chamber on the expansion stroke under the low in-cylinder pressure condition after finishing combustion. Then, the THC emission in HCCI engines is little influenced by the combustion process, in other words, the intake temperature as shown in Fig.12. It is convinced from the above results obtained in combustion tests on EGR and compression ratio that the lower compression pressure results in the lower unburned hydrocarbon emission.

\section{CONCLUSIONS}

The effect of EGR on thermal efficiency and THC emission was investigated experimentally in HCCI engines with single- and multi-cylinder fuelled with DME/NG. The concluding remarks obtained are as follows.

(1) As the EGR ratio increases, the brake thermal efficiency is improved in the whole load range by about $4 \%$ by the high $\mathrm{EGR}$ ratio of $\mathrm{X}_{\mathrm{EGR}}=0.5$.

(2) As the EGR ratio increases, the unburned hydrocarbon emission decreases remarkably.

(3) The increase in brake thermal efficiency due to EGR in $\mathrm{HCCl}$ engines is based on the improvement in combustion efficiency mainly resulting from a significant reduction in the unburned hydrocarbon emission, being not influenced by the exhaust loss and the cooling loss.

(4) It is convinced that the lower compression pressure due to EGR results in the lower unburned hydrocarbon emission, also judging from the similar result that the unburned hydrocarbon emission was decreased by reducing the compression ratio.

(5) The THC emission in HCCI engines is dependent on the fuel pre-mixture in the crevice volume, in which the temperature is dominated mainly by the liner wall temperature, in other words, the cooling water temperature, not dependent on the combustion temperature. 


\section{Acknowledgements}

The authors express their gratitude to Saibu Gas Co., Ltd., YANMAR Co., Ltd., ISUZU Motors Ltd and JSME RC220 for their supports, and also wish to thank to Messrs. Ushitani, M., Nozaki, D., Iwamura. F., Yamamoto, S., and other graduate students in Energy System Laboratory, Nagasaki University.

\section{NOMENCLATURE}

be Brake specific fuel consumption $[\mathrm{MJ} / \mathrm{kWh}]$

CA Crank angle [deg.]

$\mathrm{CO}$ Carbon monoxide emission $[\mathrm{g} / \mathrm{kWh}]$

$\mathrm{dQ} / \mathrm{d} \theta \quad$ Apparent heat release rate $[\mathrm{J} / \mathrm{deg}]$

NOx Nitrogen oxides emission $[\mathrm{g} / \mathrm{kWh}]$

n Polytropic index

$\mathrm{P} \quad$ Cylinder pressure $[\mathrm{MPa}]$

Pme Brake mean effective pressure [MPa]

PM Particulate emission reduced from Bosch smoke density $[\mathrm{g} / \mathrm{kWh}]$

$\mathrm{Q}_{\text {fuei }} \quad$ Input fuel energy $[\mathrm{J} /$ cycle/cylinder $]$

$\mathrm{Te} \quad$ Exhaust gas temperature $\left[{ }^{\circ} \mathrm{C}\right]$

$\mathrm{T}_{\mathrm{IN}} \quad$ Intake charge temperature $\left[{ }^{\circ} \mathrm{C}\right]$

THC Total unburned hydrocarbon emission $[\mathrm{g} / \mathrm{kWh}]$

$\mathrm{X}_{\mathrm{EGR}} \quad$ EGR ratio

$\varepsilon \quad$ Compression ratio

$\phi \quad$ Equivalence ratio

$\eta_{c} \quad$ Apparent combustion efficiency [\%]

$\eta_{\mathrm{e}} \quad$ Brake thermal efficiency $[\%]$

$\eta_{\text {loss-EXH }}$ Exhaust loss energy normalized by $Q_{\text {fuel }}[\%]$

$\eta_{\text {loss-COOL }}$ Cooling loss energy normalized by $Q_{\text {fuel }}[\%]$

$\eta_{\text {THC }} \quad$ THC loss energy normalized by $Q_{\text {fuel }}[\%]$

\section{Subscripts}

DME Dimethyl ether

NG Natural gas

\section{REFERENCES}

\section{JOURNALS:}

[1] Chen, Z., and Konno, M., How to Put the HCCI Engine to Practical Use: Control the Ignition Timing by Compression Ratio and Increase the Power Output by Supercharge, 2003 SAE Transactions, Journal of Fuels and Lubricants (2003) pp.1255-1263

[2] Ishida, M., Jung, S., Ueki, H. and Sakaguchi, D., Combustion of Premixed DME and Natural Gas in a HCCI Engine, SILNIKI SPALINOWE (Polish Journal of Combustion Engines) (2005); PTNSS2005, Nr.2/2005(121), pp.20-29

[3] Ishida, M., Tagai, T and Ueki, H., Effect of EGR and Preheating on Natural Gas Combustion Assisted with Gas-Oil in a Diesel Engine, JSME International Journal (2003), Series B Vol.46 No.1, pp.124-130

[4] Tagai, T., Ishida, M., Ueki, H. and Watanabe, T., Effect of Equivalence Ratio and Temperature of
CNG Premixture on Knock Limit in a Dual Fueled Diesel Engine, 2003 SAE Transactions, Journal of Fuels and Lubricants (2003), pp.1807-1816

[5] Sako, T., Sato, Y., Tanaka, H., Nakai, S. and Moriya, K., Effect of Internal Exhaust Gas Recirculation on Performance and Emissions from a Natural-Gas fueled Homogeneous Charge Compression Ignition Engine, Transactions of JSME, Ser.B, Vol.71, No.710 (2005), pp.191-196

[6] Ohmura, T., Ikemoto, M. and lida, N., A Study on Combustion Control by Using Internal and External EGR for HCCI Engines Fuelled with DME, 2006 SAE Transactions, Journal of Engines (2006), pp.1043-1052

\section{SYMPOSIUM PROCEEDINGS:}

[7] Chen, Z., Konno, M., Oguma, M. and Yanai, T., Experimental Study of CI Natural Gas/DME Homogeneous Charge Engine, SAE (2000) Paper No.2000-01-0329

[8] Konno, M. and Chen, Z., Ignition Mechanisms of HCCI Combustion Process Fuelled with Methane/DME Composite Fuel, SAE (2005) Paper No. 2005-01-0182

[9] Iida, N. et al., Basic Research on the Suitable Fuel for HCCI Engine from the Viewpoint of Chemical Reaction, SAE (2005) Paper No. 2005-01-0149

[10] Ishida, M., Jung, S., Ueki, H. and Sakaguchi, D., Effect of Exhaust Gas Recirculation on Combustion in a HCCI Engine Fueled with DME/Natural Gas, Proceedings of the International Conference on Vehicles Alternative Fuel Systems \& Environmental Protection (2006), Paper No.133, pp.61-66

[11] Ishida, M., Jung, S., Ueki, H. and Sakaguchi, D., Combustion Characteristics of HCCI Engines Fuelled with Natural Gas and DME, $25^{\text {th }}$ CIMAC (2007) Paper No.171, CD-ROM (15 Pages)

[12] Jung, S., Ishida, M., and Ueki, H., Ignition and Combustion Characteristics of DME Premixed with Natural Gas in a HCCI Engine, Proceedings of the $18^{\text {th }}$ Internal Combustion Engine Symposium (International) (2005) Paper No.20056085 (6 Pages) 